\title{
Effect of phosphorus supplementation on food intake and growth rate of rats maintained on gluten diet
}

\author{
M.E. Ragi, C. El Mallah, I. Toufeili and O. Obeid \\ Department of Nutrition and Food Sciences, American University of Beirut, Beirut, Lebanon
}

Wheat gluten is the major protein source in many developing countries. Gluten lacks some essential amino acids, primarily lysine, and, accordingly, can't foster optimal growth. For that reason, it should be complemented with a protein source containing the limiting amino acid to match human needs ${ }^{(1)}$. Further, wheat is known to contain limited amounts of available phosphorus ${ }^{(2)}$.We have recently found that the addition of phosphorus to a low protein diet (10\% egg white protein) in rats was able to attain a weight gain comparable to that of a normal protein diet $(20 \%)^{(3)}$. Therefore, a study was conducted to investigate whether phosphorus addition can affect growth of rats maintained on incomplete protein diet.

Forty male rats $(\sim 220 \mathrm{~g})$ were randomly divided into four groups and maintained on diets containing $10 \%$ protein in the form of wheat gluten $(\mathrm{G})$ with added lysine $(\mathrm{G}+\mathrm{L})$ or phosphorus $(\mathrm{G}+\mathrm{P})$ or lysine plus phosphorus $(\mathrm{G}+\mathrm{L}+\mathrm{P})$. The study was approved by the Institutional Animal Care and Use Committee (IACUC) at the American University of Beirut (AUB). Body weight and food intake were measured twice per week for 9 weeks. Average food intake, body weight and energy efficiency over the 9 weeks experimental period was calculated and data was analysed by a two way analysis of variance.

Table 1. Weight Gain $(\mathrm{g} / \mathrm{d})$, Food Intake $(\mathrm{g} / \mathrm{d})$ and Energy Efficiency $(\mathrm{g} / 100 \mathrm{Kcal})$

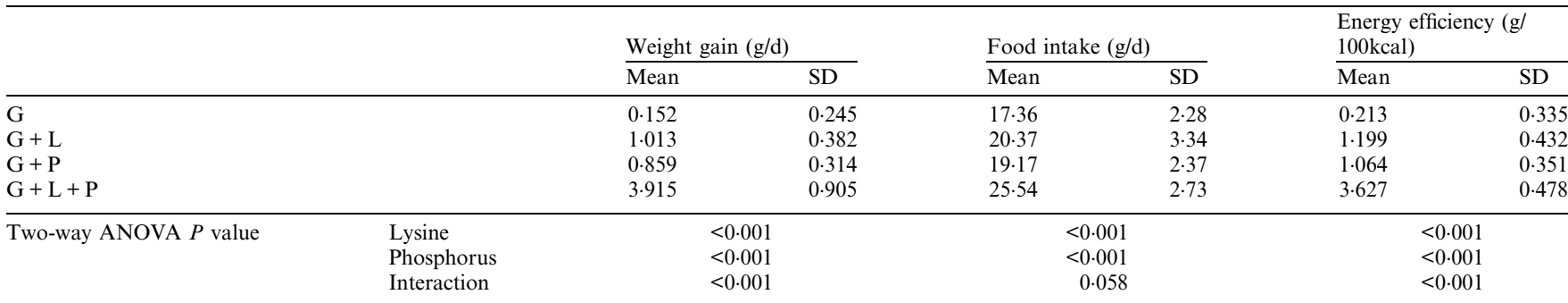

Food intake was significantly different according to lysine and phosphorus, but not the interaction. Food intake of the lysine or phosphorus groups increased by about $15 \%$, while that of both (lysine plus phosphorus) increased by about $45 \%$. Weight gain and energy efficiency were significantly different according to lysine, phosphorus and interaction. Around 5 times improvement was seen following the addition of either lysine or phosphorus, and this was further exacerbated to 20 times with the combination.

In conclusion, enhanced growth following the addition of both lysine and phosphorus seems to be mainly related to efficient energy utilization rather than increased energy intake. Moreover, a combination of the missing amino acid plus phosphorus is required to improve the quality of a gluten based diet.

1. Bos C, Juillet B, Fouillet H, et al.(2005). Am J ClinNutr 81, 87-94.

2. Calvo M and Uribarri J (2013). Dialysis 26 (1), 54-61.

3. Hammoud R, Jabbour M, Tawil A, et al. (2015) Amino Acid.; 47:1640. 